\title{
Identificação do estágio do ciclo de vida organizacional de indústrias de pequeno porte do sul de Santa Catarina
}

\author{
Rodney Wernke \\ Doutorado em Engenharia de Produção pela Universidade Federal de Santa Catarina - \\ UFSC \\ Ex-Professor universitário. Sem vínculo institucional \\ Rua Antonio Philippi, 312. Centro. São Ludgero/SC. CEP: 88730-000 \\ E-mail: rodneywernke1@hotmail.com
}

Doutorado em Engenharia de Produção pela Universidade Federal de Santa Catarina -

UFSC

Professora da Universidade do Sul de Santa Catarina - UNISUL Avenida José A. Moreira, 787. Dehon. Tubarão/SC. CEP: 88704-900 E-mail: ivone.junges@unisul.br

Arielle de Jesus Medeiros Graduação em Relações Internacionais pela Universidade do Sul de Santa Catarina UNISUL Avenida José Acácio Moreira, 787. Bairro Dehon. Tubarão/SC. CEP: 88704-900 E-mail: arielledmedeiros@gmail.com

\section{RESUMO}

O estudo objetivou identificar o estágio do ciclo de vida organizacional que prevalece nas pequenas empresas fabris localizadas nos municípios de microrregião do sul de Santa Catarina. Para essa finalidade foi realizado um levantamento de dados por meio de questionário aplicado em 88 indústrias de pequeno porte. Os resultados apontaram a prevalência dos estágios do ciclo de vida organizacional conhecidos como "crescimento" (27,27\%), "maturidade" $(23,86 \%)$ e renascimento $(22,73 \%)$, em detrimento dos estágios de "nascimento" (15,91\%) e "declínio" (10,23\%). Além disso, a hipótese de pesquisa que cogitava não haver interferência do número de funcionários no estágio do ciclo de vida da empresa foi rejeitada, pois os dois grupos amostrais mostraram médias distintas do ponto de vista estatístico pelo Mann-Whitney Test. As contribuições da pesquisa são no sentido de que $(i)$ permitiu conhecer a realidade das pequenas empresas fabris de microrregião do sul de Santa Catarina quanto aos estágios do ciclo de vida organizacional, (ii) constatou a aderência do modelo utilizado neste contexto empresarial e (iii) apontou evidência estatística sobre a influência do número de empregados no estágio do ciclo de vida de pequenas empresas.

Palavras-chave: Ciclo de vida organizacional. Contabilidade gerencial. Pequenas indústrias. 
Identificação do estágio do ciclo de vida organizacional de indústrias de pequeno porte do sul de

Santa Catarina

Rodney Wernke, Ivone Junges, Arielle de Jesus Medeiros

\section{Identification of the organizational life cycle stage of small industries in southern} Santa Catarina

\section{ABSTRACT}

The objective of this study is to identify the stage of the organizational life cycle that prevails in the small manufacturing companies located in the municipalities of microregion in the south of Santa Catarina. For that purpose, a data survey was conducted wit a questionnaire applied in 88 industries considered small. The results pointed out the prevalence of the stages of the organizational life cycle known as "growth" (27.27\%), "maturity" (23.86\%) rebirth (22.73\%), to the detriment of the stages of "birth" (15.91\%) and "decline" (10.23\%). In addition, the research hypothesis that considered there was no interference of the number of employees at the stage of the company's life cycle was rejected, since the two sample groups showed statistically different means by the Mann-Whitney Test. The present research contributions are in the sense that (i) it was possible to know the reality of the small microregion manufacturing companies in the south of Santa Catarina regarding the stages of the organizational life cycle, (ii) it was possible to verify the adherence of the model used in this business context and iii) it pointed to statistical evidence on the influence of the number of employees in the small-enterprise life cycle stage.

Key words: Organizational life cycle. Management Accounting. Small industries.

\section{Identificación de la etapa del ciclo de vida organizacional de las pequeñas industrias del sur de Santa Catarina}

\section{RESUMEN}

El estudio tuvo como objetivo identificar la etapa del ciclo de vida organizacional que prevalece en las pequeñas empresas manufactureras ubicadas en los municipios de la microrregión del sur de Santa Catarina. Para ello, se realizó una encuesta de datos mediante un cuestionario aplicado en 88 pequeñas industrias. Los resultados mostraron la prevalencia de las etapas del ciclo de vida organizacional conocidas como "crecimiento" (27,27\%), "madurez" $(23,86 \%)$ y renacimiento $(22,73 \%)$, en detrimento de las etapas de "nacimiento" (15,91\%) y "descenso" (10,23\%). Además, se rechazó la hipótesis de investigación que asumía que no existía interferencia del número de empleados en la etapa del ciclo de vida de la empresa, ya que los dos grupos de muestra arrojaron promedios diferentes desde el punto de vista estadístico por el Test de Mann-Whitney. Los aportes de la investigación son en el sentido de que (i) permitió conocer la realidad de las pequeñas empresas manufactureras de la microrregión del sur de Santa Catarina en cuanto a las etapas del ciclo de vida organizacional, (ii) verificó la adherencia del modelo utilizado en este contexto empresarial y ( iii) señaló 
Identificação do estágio do ciclo de vida organizacional de indústrias de pequeno porte do sul de

Santa Catarina

Rodney Wernke, Ivone Junges, Arielle de Jesus Medeiros

evidencia estadística sobre la influencia del número de empleados en la etapa del ciclo de vida de las pequeñas empresas.

Palabras-clave: ciclo de vida organizacional. Contabilidad Gerencial. Pequeñas industrias.

\section{INTRODUÇÃO}

As organizações são sistemas abertos que estão em constante mudança, pois são influenciadas por diversos fatores dos ambientes externo e interno, conforme Carvalho, Saraiva Junior, Frezatti e Costa (2010). Desse modo, com base na teoria relacionada ao ciclo de vida organizacional, ao longo de suas existências essas entidades passam por estágios evolutivos (Moreira, 2016; Meireles, Debastian, \& Rojo, 2015; Faveri, Cunha, Santos, \& Leandro, 2014; Marques, Cunha, Faveri, \& Walter, 2014; Pinheiro, Silva, \& Araújo, 2013; Klann, Klann, Postai, \& Ribeiro, 2012).

Oliveira, Escrivão Filho, Nagano e Ferraudo (2015) registram que o ciclo de vida organizacional tem sido utilizado como uma metáfora para designar a análise dos fenômenos relacionados às mudanças das características das organizações ao longo do tempo e às suas capacidades de adaptação ao ambiente. Portanto, as proposições do ciclo de vida organizacional podem ser aplicadas na elaboração de modelos, na demonstração de relações de causalidades das dimensões internas das organizações e para orientar a compreensão dos diferentes problemas e das possíveis soluções administrativas. Nesse sentido, Rufatto (2018) comenta que estudos acerca do ciclo de vida organizacional, como os de Quinn e Cameron (1983), Miller e Friesen (1984), Greiner (1998), Moores e Yuen (2001), Lester, Parnell e Carraher (2003), Auzair e Langfield-Smith (2005) e Dickinson (2011), têm a finalidade de analisar as características e perspectivas das organizações ao longo do tempo, visando compreender como essas se comportam e reagem às mudanças no ambiente competitivo. 
Identificação do estágio do ciclo de vida organizacional de indústrias de pequeno porte do sul de

Santa Catarina

Rodney Wernke, Ivone Junges, Arielle de Jesus Medeiros

Entretanto, no contexto das pequenas empresas é mais raro encontrar publicações que foquem esse tema, provavelmente pela reduzida base de dados disponíveis a respeito. Essa realidade também é associável às pequenas empresas industriais da microrregião da Associação dos Municípios da Região de Laguna (AMUREL), visto que nenhum estudo sobre o tema foi divulgado com o mesmo enfoque, conforme pesquisa online realizada no Portal de Periódicos da Capes em 30 de março de 2019.

Com isso, há uma lacuna de pesquisa que merece ser melhor explorada no sentido de esclarecer sobre os estágios do ciclo de vida organizacional das empresas fabris da microrregião geográfica citada. Para tanto, o caminho escolhido para fazer essa avaliação foi aplicar a metodologia desenvolvida Miller e Friesen (1984) nas empresas da amostra. Destarte, adota-se um modelo já testado em outras realidades empresariais para diagnosticar a realidade das pequenas empresas fabris da AMUREL.

Nesse rumo, nesta pesquisa pretende-se responder a seguinte questão de estudo: quais os estágios do ciclo de vida organizacional que prevalecem nas pequenas empresas industriais sediadas nos municípios da AMUREL? Para essa finalidade foi fixado o objetivo de identificar os estágios do ciclo de vida organizacional que prevalecem nas pequenas empresas fabris localizadas nos municípios da microrregião da AMUREL. Além disso, cogita-se a hipótese de que o estágio do ciclo de vida dessas empresas possa estar associado ao número de funcionários que essas mantêm, pois à medida que as organizações crescem essas tendem a requerer maior número de empregados.

O enfoque ora priorizado pode ser justificado por determinados aspectos. $\mathrm{O}$ primeiro diz respeito à relevância econômica do segmento das pequenas empresas, responsáveis por grande parte da geração de emprego e renda no Brasil (Almeida, Valadares, \& Sediyama, 2017; Santos, Dorow, \& Beuren, 2016) e também em países europeus (Malik, \& Jasinska-Biliczak, 2018; Nigri, \& Baldo, 2018). O segundo aspecto está relacionado com a escassez de estudos que focam a identificação do ciclo de vida 
Identificação do estágio do ciclo de vida organizacional de indústrias de pequeno porte do sul de

Santa Catarina

Rodney Wernke, Ivone Junges, Arielle de Jesus Medeiros

organizacional em empresas industriais de pequeno porte. Com isso, considera-se que há uma lacuna de pesquisa que este estudo pode contribuir para minimizar.

Quanto às contribuições esperadas, cogita-se obter subsídios que possibilitem conhecer a realidade das pequenas empresas fabris de uma das microrregiões do sul de Santa Catarina quanto aos estágios do ciclo de vida organizacional dessas, além de verificar a aderência do modelo utilizado sobre o ciclo de vida neste contexto empresarial e obter evidências acerca da relação do número de empregados com o estágio do ciclo de vida de indústrias de pequeno porte.

\section{REVISÃO DE LITERATURA}

A Teoria da Contingência defende que não existe uma configuração única e melhor que sirva para todas as organizações, visto que toda estrutura organizacional é afetada por diversos fatores do contexto de cada entidade (Otley, 1980). É o caso das pequenas empresas industriais abrangidas nesta pesquisa, cujos entraves para conseguirem se consolidar em mercados concorridos podem ser atribuídos a fatores contingenciais díspares (Moterle, Wernke, \& Junges, 2019; Klein \& Almeida, 2017; Callado, 2016) e serem distintos conforme o ciclo de vida organizacional.

Nesse sentido, Yh, Kh e Hj (2016) aduzem que, assim como os organismos vivos têm um ciclo de vida de nascimento-maturação-extinção, as empresas também têm um ciclo de vida organizacional composto por fases ou estágios. Em virtude disso, Manzardo, Loss, Jingzheng, Filippo e Scipioni (2018) comentam que, seguindo uma crescente demanda das empresas para entender e monitorar os potenciais impactos ambientais de suas atividades, a partir da perspectiva do ciclo de vida, a avaliação do ciclo de vida organizacional foi introduzida.

Portanto, o estudo do ciclo de vida das organizações possibilita compreender as fases de desenvolvimento em que se encontram as entidades, pois cada estágio apresenta características próprias e distintas (Silva, 2008). Além disso, permite identificar como acontece esse desenvolvimento ao longo do tempo, de vez que as 
Identificação do estágio do ciclo de vida organizacional de indústrias de pequeno porte do sul de Santa Catarina

Rodney Wernke, Ivone Junges, Arielle de Jesus Medeiros

mudanças ocorrem em padrões previsíveis e que podem ser caracterizados por estágios de desenvolvimento. Esses estágios implicam na ocorrência de transições típicas na medida em que empresas simples, jovens e pequenas tornam-se complexas, velhas e grandes (Souza, Necyk, \& Frezatti, 2008).

Pelas diversas possibilidades de pesquisa que esse tema comporta, estudos recentes utilizaram-no de modos distintos, conforme comentado na Figura 1.

\begin{tabular}{|c|c|}
\hline Autoria & Principais Aspectos \\
\hline $\begin{array}{l}\text { Santos, } \\
\text { Corrêa, } \\
\text { Beuren e } \\
\text { Gomes } \\
(2019)\end{array}$ & $\begin{array}{l}\text { Averiguaram a relação do ciclo de vida organizacional com o uso de instrumentos } \\
\text { tradicionais e modernos de Contabilidade Gerencial em } 37 \text { empresas industriais com } \\
\text { faturamento anual acima de } \mathrm{R} \$ 500 \text { mil. Os resultados mostram que a maioria dessas } \\
\text { empresas se encontra no estágio de nascimento e possuem diferentes anos de } \\
\text { constituição, não seguindo a ordem determinística preconizada na Teoria do Ciclo de } \\
\text { Vida. Concluíram, ainda, que quanto mais a empresa avança nos estágios do ciclo de } \\
\text { vida, maior é o uso de instrumentos de Contabilidade Gerencial. }\end{array}$ \\
\hline $\begin{array}{c}\text { Dufour, } \\
\text { Steane e } \\
\text { Corriveau } \\
(2018)\end{array}$ & $\begin{array}{l}\text { Objetivaram elaborar uma abordagem configuracional do pensamento estratégico para } \\
\text { avançar na compreensão do ciclo de vida organizacional. Fundamentada na análise da } \\
\text { literatura sobre o tema, a estrutura proposta destaca a natureza complexa e dinâmica do } \\
\text { pensamento e da tomada de decisões nas organizações, sugerindo um espectro de } \\
\text { várias maneiras de pensar ao longo do tempo, conforme a estratégia muda para } \\
\text { acomodar o ambiente desafiador de cada organização. Com isso, sugere que o processo } \\
\text { de desenvolvimento de estratégias não é composto por formas independentes ou } \\
\text { escolhas alternativas, mas por práticas de negócios distintas de organizações alinhadas } \\
\text { com diferentes estágios do ciclo de pensamento estratégico. }\end{array}$ \\
\hline $\begin{array}{c}\text { Almeida e } \\
\text { Wernke } \\
(2018)\end{array}$ & $\begin{array}{l}\text { Identificaram os estilos gerenciais dos dirigentes de pequenas empresas conforme o ciclo } \\
\text { de vida de } 45 \text { firmas que empregam até } 50 \text { funcionários. Em relação ao ciclo de vida, } 10 \\
\text { empresas foram classificadas no estágio } 1 \text { (Estabelecimento), } 16 \text { no estágio } 2 \text { (Direção) e } \\
19 \text { no estágio } 3 \text { (Consolidação). Quanto às atividades, distribuídas em funções e papéis, } \\
\text { as mais valorizadas em relação à abordagem de processos foram as de "planejador" e } \\
\text { "controlador" nos três estágios citados. }\end{array}$ \\
\hline $\begin{array}{l}\text { Frezatti, } \\
\text { Bido, } \\
\text { Mucci } \\
\text { e Beck } \\
(2017)\end{array}$ & $\begin{array}{l}\text { Registram que as peculiaridades das empresas familiares (como a influência exercida } \\
\text { pelos membros da família) tornam mais complexos os modelos de ciclo de vida } \\
\text { organizacional. Utilizaram o modelo de Lester, Parnell e Carraher (2003) para analisar a } \\
\text { relação entre os estágios do ciclo de vida organizacional e os elementos de influência da } \\
\text { família na empresa considerando os aspectos "poder", "experiência" e "cultura" (PEC). } \\
\text { Com amostra de } 117 \text { empresas familiares brasileiras concluíram que: os elementos do } \\
\text { PEC foram parcialmente identificados na amostra, pois o poder indica o controle da } \\
\text { empresa pela família; a experiência sinaliza o papel das diferentes gerações e a cultura } \\
\text { está associada aos valores dos controladores. Salientaram que no estágio de } \\
\text { "nascimento" o poder e a cultura têm papéis importantes, enquanto na "maturidade" são } \\
\text { a experiência e a cultura que se destacam. Além disso, na fase do "rejuvenescimento" o } \\
\text { poder e a cultura foram identificados como caracterizadores. }\end{array}$ \\
\hline $\begin{array}{c}\text { TenBrink } \\
\text { e Gelb } \\
\text { (2017) }\end{array}$ & $\begin{array}{l}\text { Fizeram avaliação baseada em pesquisas sobre porque empresas maduras, em } \\
\text { indústrias maduras, podem ter dificuldades para sobreviver. As questões básicas } \\
\text { exploradas são grandes obstáculos ao caminho dinâmico que a teoria da contingência } \\
\text { poderia prever. Examinando dezenas de estudos através das lentes da teoria do ciclo de } \\
\text { vida organizacional, os autores investigam como a própria maturidade organizacional }\end{array}$ \\
\hline
\end{tabular}




\begin{tabular}{|c|c|}
\hline & $\begin{array}{l}\text { impede melhores escolhas. Concluíram que mudanças ambientais no mercado, políticas } \\
\text { rígidas, procedimentos demorados e políticas focalizadas internamente, muitas vezes, } \\
\text { dificultam a mudança. }\end{array}$ \\
\hline $\begin{array}{l}\text { Tam e } \\
\text { Gray } \\
(2016)\end{array}$ & $\begin{array}{l}\text { Exploraram como os funcionários de } 30 \text { pequenas e médias empresas (PMEs) de Hong } \\
\text { Kong praticam e veem a aprendizagem no local de trabalho em três estágios diferentes } \\
\text { do ciclo de vida. As entrevistas realizadas identificaram padrões em termos de } \\
\text { semelhanças e diferenças na natureza da prática de aprendizagem no local de trabalho } \\
\text { nas PME entre os estágios do ciclo de vida. Concluíram que, se o crescimento } \\
\text { organizacional é uma prioridade, os proprietários/gerentes das PMEs deveriam apoiar o } \\
\text { trabalho e a aprendizagem dos funcionários em tempo hábil, pois o aprendizado } \\
\text { individual e o aprendizado interorganizacional são considerados "obrigatórios" para os } \\
\text { funcionários, independentemente de qual estágio a empresa está. Porém, quando uma } \\
\text { PME entra em alto crescimento, mais oportunidades para aprendizagem em grupo são } \\
\text { particularmente benéficas. Para PMEs maduras é essencial aprender a avançar para a } \\
\text { sistematização e incluir um componente de desenvolvimento profissional para atender às } \\
\text { expectativas de carreira dos funcionários, não apenas às demandas de trabalho. }\end{array}$ \\
\hline $\begin{array}{c}\text { Primc e } \\
\text { Cater } \\
(2016)\end{array}$ & $\begin{array}{l}\text { Baseando-se na visão de capacidades dinâmicas, examinaram empiricamente as } \\
\text { relações entre a proatividade ambiental, os estágios do ciclo de vida organizacional, a } \\
\text { vantagem competitiva e a indústria em uma amostra de } 155 \text { empresas australianas. Os } \\
\text { resultados mostram que o construto do ciclo de vida organizacional está } \\
\text { significativamente relacionado à proatividade ambiental. Os resultados também } \\
\text { confirmam o impacto positivo bem estabelecido da proatividade ambiental na vantagem } \\
\text { competitiva e, ainda, que a proatividade ambiental estava positivamente relacionada à } \\
\text { vantagem competitiva, não apenas nos estágios inovadores, mas também nos } \\
\text { conservadores. }\end{array}$ \\
\hline $\begin{array}{l}\text { Lima e } \\
\text { Vasconcelos } \\
(2016)\end{array}$ & $\begin{array}{l}\text { Investigaram a relação entre os estágios do ciclo de vida organizacional de } 41 \text { empresas } \\
\text { de base tecnológica incubadas (EBTIs) e a estrutura de ativos intangíveis destas. A } \\
\text { identificação dos estágios do ciclo de vida e o exame da estrutura de ativos intangíveis } \\
\text { foram realizados por meio das obras de Scott e Bruce (1987) e Sveiby (1998), } \\
\text { respectivamente, sendo que os resultados demonstram que a estrutura de ativos } \\
\text { intangíveis das EBTls altera-se à medida que as organizações progridem em seus } \\
\text { estágios do ciclo de vida organizacional. }\end{array}$ \\
\hline $\begin{array}{c}\text { Oliveira, } \\
\text { Escrivão } \\
\text { Filho, } \\
\text { Nagano e } \\
\text { Ferraudo } \\
\text { (2015) }\end{array}$ & $\begin{array}{l}\text { Buscaram identificar os estilos gerenciais dos dirigentes de pequenas empresas em cada } \\
\text { estágio do ciclo de vida organizacional, considerando o trabalho do administrador, } \\
\text { abordagens do processo e dos papéis. Participaram do estudo } 70 \text { empresas } \\
\text { pertencentes ao setor metalúrgico-mecânico do Estado de São Paulo. As características } \\
\text { da diversidade de comportamentos entre a grande e a pequena empresa podem ser } \\
\text { evidenciadas pela teoria do Ciclo de Vida Organizacional, a qual pressupõe que os } \\
\text { problemas e as soluções administrativas apresentadas pelas organizações são diferentes } \\
\text { conforme o estágio em que elas se encontram. Como resultados, verificaram que os } \\
\text { dirigentes das pequenas empresas mudam a valorização das funções e dos papéis do } \\
\text { administrador conforme o estágio de desenvolvimento da firma. }\end{array}$ \\
\hline $\begin{array}{c}\text { Su, } \\
\text { Baird e } \\
\text { Schoch } \\
(2015)\end{array}$ & $\begin{array}{l}\text { Examinaram a associação entre as abordagens interativa e diagnóstica do uso de } \\
\text { controles e os estágios do ciclo de vida organizacional de Miller e Friesen (1984), numa } \\
\text { amostra aleatória de } 343 \text { gerentes de empresas de manufatura australianas. Os } \\
\text { resultados indicam que ambas as abordagens são usadas em maior extensão nos } \\
\text { estágios de crescimento e renascimento do que os estágios de nascimento e maturidade, } \\
\text { enquanto as abordagens interativa e diagnóstica são usadas em uma extensão similar } \\
\text { em cada um dos estágios do ciclo de vida. Assim, contribuem com a literatura ao adotar a } \\
\text { abordagem de configuração para examinar como múltiplas variáveis contingentes afetam } \\
\text { simultaneamente a abordagem de uso de controles, além de examinar como as } \\
\text { organizações ajustam sua ênfase nas abordagens interativas e diagnósticas para usar }\end{array}$ \\
\hline
\end{tabular}




\begin{tabular}{|c|c|}
\hline & ntroles à medida que se movem em diferentes estágios de desenvolvimento. \\
\hline $\begin{array}{c}\text { Beuren, } \\
\text { Rengel e } \\
\text { Rodrigues } \\
\text { Junior (2015) }\end{array}$ & $\begin{array}{l}\text { Pesquisaram se existe relação entre o uso de atributos da contabilidade gerencial e as } \\
\text { fases do ciclo de vida organizacional, numa amostra composta por } 40 \text { gestores de } \\
\text { empresas do segmento industrial de máquinas, equipamentos e materiais elétricos de } \\
\text { Santa Catarina. Os resultados mostram que os atributos de contabilidade gerencial, nos } \\
\text { aspectos de seleção e apresentação de informações, são mais utilizados em empresas } \\
\text { que estão nas fases de crescimento e rejuvenescimento, do que naquelas classificadas } \\
\text { nas fases de nascimento e declínio. Concluíram que existe relação entre o uso dos } \\
\text { atributos da contabilidade gerencial e a evolução nas fases do ciclo de vida das } \\
\text { empresas investigadas. }\end{array}$ \\
\hline $\begin{array}{c}\text { Campos, } \\
\text { Parellada, } \\
\text { Atondo e } \\
\text { Quintero } \\
(2015)\end{array}$ & $\begin{array}{l}\text { Comentam que não há pesquisas suficientes sobre as maneiras pelas quais os } \\
\text { empreendedores tomam decisões estratégicas nos estágios iniciais do ciclo de vida } \\
\text { organizacional. Portanto, analisaram os efeitos dos fatores associados ao tomador de } \\
\text { decisão influenciando a orientação estratégica e o desempenho de duas categorias de } \\
\text { empresas. Os resultados foram obtidos usando dados empíricos de duas amostras } \\
\text { independentes de empresas em diferentes estágios do ciclo de vida organizacional. Os } \\
\text { resultados mostram que as variáveis de tomada de decisão estratégica e controle têm } \\
\text { diferentes efeitos nas duas amostras, mas para ambas as amostras há relação } \\
\text { significativa entre orientação estratégica e desempenho. }\end{array}$ \\
\hline $\begin{array}{c}\text { Souza, } \\
\text { Guerreiro } \\
\text { e Oliveira } \\
(2015)\end{array}$ & $\begin{array}{l}\text { Abordaram a relação entre o nível de maturidade do gerenciamento de processos da } \\
\text { cadeia de suprimentos (SCPM) e o ciclo de vida organizacional de uma amostra de } 228 \\
\text { empresas brasileiras. Entre as principais conclusões, destacam-se evidências de uma } \\
\text { relação entre o nível de maturidade do SCPM e o estágio do ciclo de vida das empresas } \\
\text { pesquisadas. Além disso, verificaram que o nível de maturidade do SCPM não tem } \\
\text { relação significativa com a idade ou o tamanho de uma empresa, mas está relacionado } \\
\text { às capacidades inerentes ao SCPM. }\end{array}$ \\
\hline
\end{tabular}

\section{Figura 1. Pesquisas recentes sobre Ciclo de Vida Organizacional}

Fonte: elaborada pelos autores.

Quanto a modelos para mensurar o ciclo de vida organizacional, Rufatto (2018) evidencia aqueles que vêm sendo mais utilizados e as respectivas fases ou estágios que os integram, conforme elencado na Tabela 1. 
Identificação do estágio do ciclo de vida organizacional de indústrias de pequeno porte do sul de

Santa Catarina

Rodney Wernke, Ivone Junges, Arielle de Jesus Medeiros

Tabela 1

Modelos de Mensuração do Ciclo de Vida Organizacional

\begin{tabular}{ll}
\hline Autoria & \multicolumn{1}{c}{ Fases ou Estágios do Ciclo de Vida Organizacional } \\
\hline Quinn e Cameron (1983) & Estágio Empreendedor, Estágio de Coletividade, Estágio de \\
& Formalização e Controle e Estágio de Formação de Estrutura \\
\hline Miller e Friesen (1984) & Nascimento, Crescimento, Maturidade, Renascimento e Declínio \\
\hline Adizes (1990) & $\begin{array}{l}\text { Infância, Toca-toca, Adolescência, Plenitude, Estabilidade, } \\
\text { Aristocracia, Paranoia, Burocracia e Morte }\end{array}$ \\
\hline Greiner (1998) & Criatividade, Sobrevivência, Sucesso/Decolagem, Expansão e \\
& Maturidade \\
\hline Moores e Yuen (2001) & Nascimento, Crescimento, Maturidade, Renascimento e Declínio \\
\hline Lester, Parnell e Carraher & Existência, Sobrevivência, Sucesso, Rejuvenescimento e Declínio \\
(2003) & \\
\hline Auzair e Langfield-Smith (2005) & Formação, Crescimento e Maturidade \\
\hline Dickinson (2011) & Introdução, Crescimento, Maturidade, Turbulência e Declínio \\
\hline
\end{tabular}

Nota. Fonte: Adaptada de Rufatto (2018).

Das pesquisas citadas é interessante salientar a proposição de Miller e Friesen (1984), que foi priorizado nesta pesquisa porque esse se destacou por sua profundidade conceitual e pelo embasamento empírico, além de ter fundamentado vários outros estudos. Provavelmente isso ocorreu porque os referidos autores elaboraram uma tipologia que pode ser utilizada para prever diferenças entre características ambientais e organizacionais (como diferenças na estratégia, na estrutura ou no estilo de tomada de decisão) em distintos estágios do ciclo de vida organizacional (Rufatto, 2018).

Miller e Friesen (1984) partiram de uma revisão de literatura que reconhece as mudanças organizacionais como previsíveis e que seguem uma progressão hierárquica onde os diferentes estágios percorrem uma sequência de complementaridade entre variáveis distribuídas à luz de quatro variáveis: ambiente, estrutura, estratégia e tomada de decisão. Tal proposição está fundamentada no conceito denominado "configuração", que está calcado em um conjunto de elementos conectados e alinhados com uma determinada dimensão (como a estrutura da empresa, por exemplo). Assim, a relevância teórica e prática desse modelo consiste na possibilidade de se prever 
Identificação do estágio do ciclo de vida organizacional de indústrias de pequeno porte do sul de

Santa Catarina

Rodney Wernke, Ivone Junges, Arielle de Jesus Medeiros

detalhes da estrutura organizacional de uma empresa a partir de fatores organizacionais que caracterizem sua configuração.

Quanto a estudos anteriores que empregaram o modelo proposto por Miller e Friesen (1984) é cabível elencar os de Souza, Necyk e Frezatti (2008), Carvalho et al. (2010), Klann et al. (2012), Santos (2014), Carpes (2015), Beuren e Oliveira (2015), Moreira (2016), Silva (2016), Santos (2017) e Rufatto (2018). Ademais, a justificativa para utilização do modelo de Miller e Friesen (1984) neste estudo está fundamentada no fato de que tal instrumento é aplicável a diferentes universos organizacionais afetados por diversos fatores contingenciais, como é o caso das indústrias de pequeno porte priorizadas neste estudo.

Por outro lado, no que tange ao aspecto do porte, nesta pesquisa foi utilizado o critério relacionado ao número de funcionários das empresas abrangidas para segregálas em micros e pequenas empresas. Para tanto, utilizou-se o parâmetro adotado pelo Sebrae (2019), que classifica como microempresas aquelas indústrias que possuem até 19 pessoas ocupadas, enquanto que as empresas de pequeno porte são as que têm de 20 a 99 empregados.

O porte de um empreendimento é um fator importante e pode afetar a estrutura organizacional respectiva porque, a priori, uma empresa de porte maior reúne condições mais favoráveis para aproveitar as oportunidades para expansão das operações (Klein, \& Almeida, 2017). Em virtude disso, considerou-se que nesse estrato de pequenas empresas, aquelas de porte menor (classificáveis como microempresas) provavelmente estariam situadas em estágios mais iniciais do ciclo de vida organizacional, enquanto que as enquadráveis como de pequeno porte (entre 20 e 99 funcionários) estariam em estágios mais avançados.

Nesse sentido, cogitou-se as seguintes hipóteses de pesquisa: o estágio do ciclo de vida organizacional que prevalece é igual entre os dois grupos de empresas pesquisadas (hipótese nula), enquanto que na hipótese alternativa admite-se que o estágio que prevalece seria diferente, pois à medida que as organizações crescem estas tendem a ter um quadro funcional maior. 
Identificação do estágio do ciclo de vida organizacional de indústrias de pequeno porte do sul de

Santa Catarina

Rodney Wernke, Ivone Junges, Arielle de Jesus Medeiros

\section{METODOLOGIA}

No que tange aos aspectos metodológicos desta pesquisa, em relação à tipologia (natureza) quanto aos objetivos cabe classificá-la como descritiva, visto que Andrade (2002) assim classifica os estudos que se preocupam em observar os fatos, registrá-los, analisá-los, classificá-los e interpretá-los sem a interferência direta do pesquisador no contexto. No caso da forma de abordagem, a presente pesquisa se enquadra como quantitativa, pois Richardson (1999) aduz que essa modalidade envolve os estudos que empregam a quantificação, tanto nas modalidades de coleta de informações, quanto no tratamento dessas por meio de técnicas estatísticas, desde as mais simples (como percentual, média, desvio padrão etc.) até aquelas mais complexas (como coeficientes de correlação, análises de regressão etc.). Quanto aos procedimentos para coligir dados foi escolhida a técnica do levantamento ou survey (Gil, 2002), instrumentalizada por intermédio de questionário aplicado aos participantes.

A respeito do corpus da pesquisa (população abrangida), convém salientar que a amostra a ser utilizada foi extraída da população composta pelas pequenas empresas industriais da microrregião da AMUREL, cujos gestores concordaram participar. Portanto, a priori esta amostra tem caráter não probabilístico, visto que sua abrangência se vinculará ao critério de acessibilidade por parte dos pesquisadores. Nesse sentido foram estabelecidos como critérios para participar da pesquisa as características de (I) ser empresa fabril com até 100 funcionários e (ii) estar sediada na microrregião da AMUREL.

Quanto ao instrumento utilizado para coligir os dados é pertinente destacar que a coleta de dados ocorreu no primeiro semestre de 2019, mediante a aplicação de questionário específico, elaborado com base no modelo proposto por Miller e Friesen (1984) e que já foi replicado em outras pesquisas (Souza, Necyk e Frezatti, 2008; Carvalho et al., 2010; Klann et al., 2012; Santos, 2014; Carpes, 2015; Beuren e Oliveira, 2015; Moreira, 2016; Silva, 2016; Santos, 2017; Rufatto, 2018), além de servir de base para outros modelos. No caso deste estudo, os questionários foram preenchidos online 
Identificação do estágio do ciclo de vida organizacional de indústrias de pequeno porte do sul de

Santa Catarina

Rodney Wernke, Ivone Junges, Arielle de Jesus Medeiros

(na ferramenta Google Forms) a partir das informações coligidas junto aos gestores de empresas fabris. Esses foram contatados por intermédio das associações empresariais da região geográfica selecionada, mediante envio de e-mail contendo o link do formulário respectivo, bem como de modo presencial pelos alunos/bolsistas envolvidos nesta pesquisa.

O questionário foi composto por três partes: a primeira com 19 perguntas sobre as características dos respondentes e das empresas participantes; enquanto que a segunda continha seis indagações relacionadas ao desempenho perante os concorrentes diretos e a terceira parte com 40 questões acerca dos estágios do ciclo de vida organizacional. No caso deste último grupo, as questões previam cinco opções de respostas: "1 - Discordo totalmente", "2 - Discordo parcialmente", "3 Indiferente/Neutro", "4 - Concordo parcialmente" e "5 - Concordo totalmente".

No que se refere à análise dos dados, primeiramente foi feita a tabulação em planilha Excel onde foi empregada a estatística descritiva (frequência e número de respostas) para sintetizar os resultados e facilitar a interpretação dos "achados" do estudo. Em seguida, para verificar a normalidade dos dados foi utilizado o teste Kolmogorov-Smirnov, que analisa se os dados da amostra foram extraídos de uma população com distribuição normal (Bruni, 2012). Então, conforme avaliação extraída do software Statistical Package for Social Sciences (SPSS), o resultado oriundo indicou "Sig. Assint. (2 caudas) = 0,009", cuja interpretação indica que por ser inferior a 0,05 é pertinente considerar que a variável abrangida não tem distribuição normal (Field, 2009).

Em decorrência da constatação de não normalidade dos dados optou-se por aplicar o teste não paramétrico Mann-Whitney, que é recomendado para análise de duas amostras independentes (neste caso, uma composta por empresas com até 19 funcionários e outra formada por indústrias com quadro que abrange entre 20 e 99 empregados), que serve como uma alternativa ao "T-Test" e baseia sua análise em médias dos grupos (Rauen, 2015; Bruni, 2012; Triola, 2005). Esse teste foi aplicado para verificar a seguinte hipótese acerca dos dois grupos de pequenas indústrias 
abrangidas, ou seja, de que o estágio do ciclo de vida organizacional que prevalece é igual entre os dois grupos de empresas em lume (hipótese nula).

Quanto aos resultados oriundos do Mann-Whitney Test, Bruni (2012) assevera que devem ser interpretados da seguinte forma: (I) se "Sig > 0,05" não se pode rejeitar a hipótese nula $(\mathrm{H} 0)$, aceitando-se o fato da existência de igualdade entre os grupos testados e (ii) se "Sig < 0,05" refuta-se a hipótese nula $(\mathrm{H} 0)$, rejeitando-se o fato de existir igualdade entre os grupos abrangidos.

Além disso, para consolidar os resultados quanto ao ciclo de vida organizacional, o levantamento da pontuação das respostas para classificar nos estágios do modelo de Miller e Friesen (1984) inicialmente levou à definição em 65 empresas. Contudo, no caso das outras 23 empresas (26,14\%) ocorreu "empate" em mais de um estágio, o que requereu a aplicação do cálculo da entropia da informação.

Rocha (2010) descreve o cálculo da entropia informacional da seguinte forma:

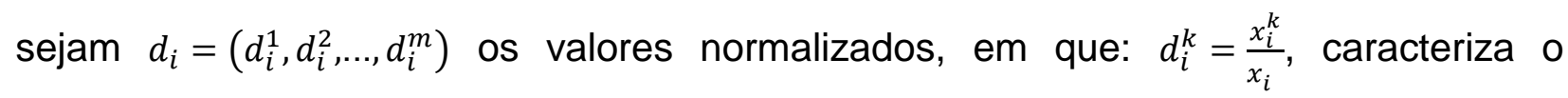
conjunto $\mathrm{D}$, em termos do i-ésimo atributo. Encontra-se $D_{i}=\sum_{k=1}^{m} d_{i}^{k} ; i=1,2, \ldots, n$. Buscase, então, a medida de entropia do contraste de intensidade para o i-ésimo atributo calculado por $e\left(d_{i}\right)=-\alpha \sum_{k=1}^{m} \frac{d_{i}^{k}}{D_{i}} \operatorname{Ln}\left(\frac{d_{i}^{k}}{D_{i}}\right)$, em que $\alpha=\frac{1}{e_{\max }}>0$ e $\mathrm{e}_{\max }=\operatorname{Ln}(\mathrm{m})$, bem como observa-se que $0 \leq d_{i}^{k} \leq 1$ e $d_{i}^{k} \geq 0$. Caso todos os $d_{i}^{k}$ forem iguais para um dado $\mathrm{i}$, então $\frac{d_{i}^{k}}{D_{i}}=\frac{1}{n} \mathrm{e} \mathrm{e}\left(\mathrm{d}_{\mathrm{i}}\right)$ assume o valor máximo, isto é, $e_{\max }=\operatorname{Ln}(\mathrm{m})$. Ao se fixar $\alpha=\frac{1}{e_{\max }}$, determina-se $0 \leq e\left(d_{i}\right) \leq 1$ para todos os $\mathrm{e}\left(\mathrm{d}_{\mathrm{i}}\right) \mathrm{s}$, sendo que essa normalização é necessária para efeito comparativo. Desse modo, a entropia total de $D$ é definida por: $E=\sum_{i=1}^{n} e\left(d_{i}\right)$, o que implica que quanto maior for $\mathrm{e}\left(\mathrm{d}_{\mathrm{i}}\right)$, menor é a informação transmitida pelo i-ésimo atributo. Caso $\mathrm{e}\left(\mathrm{d}_{\mathrm{i}}\right)=\mathrm{e}_{\max }=\mathrm{Ln}(\mathrm{m})$, então o i-ésimo atributo não transmite informação e pode ser removido da análise decisória. Em virtude do peso $\tilde{\lambda}_{i}$ ser inversamente relacionado a e $\left(d_{i}\right)$, usa-se 1-e $\left(d_{i}\right)$ ao invés de $e\left(d_{i}\right)$ e normaliza-se para assegurar que $0 \leq \tilde{\lambda}_{i} \leq 1$ e $\sum_{i=1}^{n} \tilde{\lambda}_{i}=1$. 
Identificação do estágio do ciclo de vida organizacional de indústrias de pequeno porte do sul de

Santa Catarina

Rodney Wernke, Ivone Junges, Arielle de Jesus Medeiros

\section{APRESENTAÇÃO DOS DADOS E DISCUSSÃO DOS RESULTADOS}

As próximas seções descrevem os principais aspectos relacionados aos respondentes, às empresas pesquisadas e à metodologia utilizada para identificação do estágio do ciclo de vida organizacional nos quais as pequenas empresas fabris em estudo estão posicionadas.

\subsection{Características dos respondentes e das empresas}

As respostas coligidas permitiram conhecer o perfil dos 88 (oitenta e oito) respondentes, cujas principais peculiaridades são as seguintes:

a) Tipo de vínculo com a empresa: a maior parte dos respondentes é composta por proprietários/sócios $(39,77 \%)$ ou funcionários $(39,77 \%)$, enquanto houve uma menor participação dos gestores (20,46\%);

b) Tempo de atuação na função atual: uma pequena parcela $(9,09 \%)$ dos participantes possui experiência menor que dois anos na atividade atualmente desempenhada na empresa. Os percentuais mais elevados foram verificados entre 2,1 e 5 anos (com 29,55\% do total) e entre 5,1 e 10 anos (32,95\% dos participantes). Além disso, 10,23\% dos respondentes mencionaram atuar entre 10,1 e 15 anos, outros 10,23\% citaram que atuam há mais de 20 anos na função e 7,95\% assinalaram a opção de que estão trabalhando no cargo atual entre 15,1 e 20 anos;

c) Nível de escolaridade: a tabulação das respostas indicou que 22 respondentes $(25,00 \%$ do total) têm até o segundo grau completo, enquanto que onze participantes (12,50\%) começaram, mas não concluíram, o terceiro grau e 34 responderam que já têm ensino superior completo $(38,64 \%)$. No que tange à Pós-Graduação, apenas quinze respondentes citaram ter concluído curso deste nível e seis alegaram que ainda não concluíram esta fase de estudos; 
Identificação do estágio do ciclo de vida organizacional de indústrias de pequeno porte do sul de

Santa Catarina

Rodney Wernke, Ivone Junges, Arielle de Jesus Medeiros

d) Curso de graduação: entre os 55 que fizeram cursos de graduação, a área predominante foi a da Administração e apenas cinco respondentes tiveram formação universitária em outro ramo do conhecimento;

e) Curso de Pós-Graduação: dos quinze que responderam ter concluído este tipo de curso, dez estudaram na área administrativa e os demais cinco em ramos distintos.

Quanto às características das empresas abrangidas pelo estudo é pertinente salientar os aspectos descritos abaixo:

1) Número de funcionários: 58 das entidades participantes (ou seja, 65,90\% do total) possuem entre 20 e 99 funcionários (pequenas empresas), enquanto 26 indústrias (equivalente a 29,55\%) têm até 19 funcionários (microempresas) e somente quatro contavam apenas com o trabalho do proprietário (4,55\%);

2) Configuração jurídica: a formatação predominante foi a de empresas "Limitada" (sociedades por quotas de responsabilidade limitada), com $69,32 \%$ das participantes. O segundo maior grupo foi composto pelas "Eireli" (empresa individual de responsabilidade limitada), com $15,91 \%$ do total de respostas e o terceiro conjunto foi formado pelos "MEl" (microempreendedores individuais), pois as 13 empresas dessa categoria representaram $14,77 \%$ do conjunto pesquisado;

3) Enquadramento tributário: as optantes pelo Simples formaram o maior grupo (com $67,55 \%$ do total) e foram seguidas pelas empresas que escolheram o Lucro Presumido (17,05\%) e o Lucro Real (15,40\%).

4) Tipo de indústria: a respeito dessa característica, as respostas identificaram que a maior concentração ocorreu nos segmentos de "confecção de artigos do vestuário e acessórios" (14,77\%), "alimentícios" (13,64\%), "borracha e material plástico" $(11,36 \%)$ e metalurgia (6,82\%). Além desses, algumas empresas classificavam-se como fábricas de "máquinas e equipamentos", "móveis", "bebidas", "madeira", "químicos", "minerais não metálicos", "produtos de 
Identificação do estágio do ciclo de vida organizacional de indústrias de pequeno porte do sul de Santa Catarina

Rodney Wernke, Ivone Junges, Arielle de Jesus Medeiros

limpeza/higiene pessoal", "têxteis (exceto confecções)" e "outros tipos de indústria".

\subsection{Avaliação do desempenho recente perante a concorrência}

$\mathrm{Na}$ segunda parte do questionário aplicado foi indagado acerca da opinião do respondente quanto à performance da empresa em relação a seus competidores diretos nos últimos 12 meses. Nesse sentido, inicialmente convém esclarecer que se adotou a expressão "competidores diretos" para designar aquela parte da concorrência que disputa a mesma fatia de mercado, o que é diferente de todos os possíveis concorrentes do mesmo ramo de negócio.

Assim, na Tabela 2 estão deslindados os resultados oriundos do levantamento efetuado junto às empresas em lume.

Tabela 2

Evolução recente perante os competidores diretos (últimos 12 meses)

\begin{tabular}{lccc}
\hline Itens & $\begin{array}{c}\text { Discorda total ou } \\
\text { parcialmente (\%) }\end{array}$ & $\begin{array}{c}\text { Indiferente ou } \\
\text { Neutro (\%) }\end{array}$ & $\begin{array}{c}\text { Concorda total ou } \\
\text { Parcialmente (\%) }\end{array}$ \\
\hline Faturamento maior que competidores & 21,59 & 35,23 & 43,18 \\
$\begin{array}{l}\text { Lucro líquido maior que competidores } \\
\text { Retorno do investimento maior que }\end{array}$ & 22,73 & 42,05 & 35,23 \\
$\begin{array}{l}\text { competidores } \\
\text { Participação de mercado maior que }\end{array}$ & 17,05 & 40,91 & 42,05 \\
$\begin{array}{l}\text { competidores } \\
\text { Satisfação de clientes maior que }\end{array}$ & 14,77 & 13,64 & 71,59 \\
$\begin{array}{l}\text { competidores } \\
\text { Número de novos clientes maior que }\end{array}$ & 26,14 & 40,91 & 32,95 \\
competidores & 11,36 & 26,14 & 62,50 \\
\hline
\end{tabular}

Nota. Fonte: elaborada pelos autores.

No que tange à evolução do faturamento, a maioria dos respondentes $(43,18 \%)$ informou acreditar que suas empresas superaram o desempenho de seus competidores diretos. Contudo, 35,23\% optaram por assinalar a opção "indiferente ou neutro" e $21,59 \%$ discordaram que tenha sido maior que a concorrência. 
Identificação do estágio do ciclo de vida organizacional de indústrias de pequeno porte do sul de Santa Catarina

Rodney Wernke, Ivone Junges, Arielle de Jesus Medeiros

Quando inquiridos se o lucro líquido foi maior que o dos competidores, 22,73\% citaram que o desempenho foi inferior e $35,23 \%$ opinaram que foi superior. Entretanto, o maior contingente $(42,05 \%)$ asseverou que essa performance foi "indiferente ou neutra", o que indica que provavelmente foi semelhante àquela estimativa feita para os concorrentes diretos.

A pergunta que procurou conhecer se o retorno do investimento foi maior que 0 obtido pelos competidores, mostrou que $42,05 \%$ dos respondentes aduziram que suas empresas devem ter superado seus rivais neste parâmetro de avaliação. Esse percentual é ligeiramente superior aos que assinalaram a alternativa "indiferente ou neutro" $(40,91 \%)$ e bem distante do contingente de empresas que não superaram aquelas com as quais competem.

$\mathrm{Na}$ questão que abordou se a participação de mercado era maior que a fatia dominada pelos competidores diretos foi constatado que $71,59 \%$ dos respondentes concorda (total ou parcialmente) que suas empresas suplantaram as demais do segmento onde atuam. Porém, em $14,77 \%$ das respostas restou evidenciado que o domínio de mercado foi menor e apenas $13,64 \%$ declararam-se neutros ou indiferentes a respeito.

Quanto ao aspecto de conseguir satisfação de clientes maior que a conseguida pelos competidores diretos, a maior parte das respostas situou-se no estrato de "indiferente/neutro". Além disso, 32,95\% defendem que conseguem superar as outras empresas e $26,14 \%$ entendem que ficaram aquém dos concorrentes nesse quesito.

Ao indagar sobre a capacidade de prospectar novos clientes, a maioria das empresas $(62,50 \%)$ revelou que é capaz de superar os competidores nessa variável. Mas, $11,36 \%$ das companhias abrangidas não conseguiram superar os rivais e $26,14 \%$ ficaram no nível intermediário (indiferente ou neutro).

\subsection{Resultados quanto ao ciclo de vida organizacional das empresas abrangidas}

A terceira parte do questionário abrangeu 40 perguntas, subdivididas em grupos de oito questões para cada um dos cinco estágios do ciclo de vida organizacional 
Identificação do estágio do ciclo de vida organizacional de indústrias de pequeno porte do sul de Santa Catarina Rodney Wernke, Ivone Junges, Arielle de Jesus Medeiros

(nascimento, crescimento, maturidade, renascimento e declínio) e objetivou identificar o estágio que melhor representaria o posicionamento atual das pequenas empresas fabris pesquisadas.

As opções de respostas envolviam cinco possibilidades que iam de "1-Discordo totalmente" a "2-Discordo parcialmente", "3-Indiferente/neutro", "4-Concordo parcialmente" e "5-Concordo totalmente". Desse modo, os respondentes assinalavam o nível de " 1 " a "5" que mais se aproximava do contexto empresarial que representavam e a pontuação alcançada em cada uma das oito questões servia para definir o estágio no qual se enquadrava a empresa, conforme exemplificado na Tabela $3 \mathrm{com}$ apenas dez das 88 empresas da amostra utilizada.

Tabela 3

Pontuação obtida em cada estágio do ciclo de vida organizacional (10 primeiras empresas)

\begin{tabular}{lccccc}
\hline Empresa & $\begin{array}{c}\text { Estágio do } \\
\text { Nascimento }\end{array}$ & $\begin{array}{c}\text { Estágio do } \\
\text { Crescimento }\end{array}$ & $\begin{array}{c}\text { Estágio da } \\
\text { Maturidade }\end{array}$ & $\begin{array}{c}\text { Estágio do } \\
\text { Renascimento }\end{array}$ & $\begin{array}{c}\text { Estágio do } \\
\text { Declínio }\end{array}$ \\
\hline 1 & 28 & 28 & 30 & 28 & 29 \\
2 & 22 & 32 & 29 & 26 & 26 \\
3 & 27 & 33 & 28 & 33 & 34 \\
4 & 37 & 36 & 28 & 34 & 28 \\
5 & 28 & 30 & 28 & 29 & 25 \\
6 & 29 & 29 & 28 & 28 & 25 \\
7 & 23 & 27 & 27 & 31 & 24 \\
8 & 26 & 27 & 30 & 19 & 20 \\
9 & 27 & 35 & 33 & 32 & 19 \\
10 & 31 & 14 & 23 & 27 & 22 \\
\hline
\end{tabular}

Nota. Fonte: elaborada pelos autores.

No caso da empresa "1" a pontuação maior ficou com o estágio "Maturidade" (com 30 pontos), enquanto que a empresa "2" alcançou valor superior no estágio "Crescimento" etc. Desse modo, o referido levantamento permitiu classificar essas indústrias nos moldes da realidade descrita na Tabela 4 
Identificação do estágio do ciclo de vida organizacional de indústrias de pequeno porte do sul de Santa Catarina Rodney Wernke, Ivone Junges, Arielle de Jesus Medeiros

Tabela 4

Classificação por estágios (antes da Entropia)

\begin{tabular}{lcc}
\hline Estágios & Quantidade de empresas & $\%$ do total \\
\hline Nascimento & 12 & $13,64 \%$ \\
Crescimento & 19 & $21,59 \%$ \\
Maturidade & 14 & $15,91 \%$ \\
Renascimento & 16 & $18,18 \%$ \\
Declínio & 4 & $4,55 \%$ \\
Crescimento/Renascimento & 4 & $4,55 \%$ \\
Crescimento/Maturidade & 3 & $3,41 \%$ \\
Nascimento/Crescimento & 3 & $3,41 \%$ \\
Crescimento/Maturidade/Renascimento & 2 & $2,27 \%$ \\
Maturidade/Declínio & 2 & $2,27 \%$ \\
Maturidade/Renascimento & 2 & $2,27 \%$ \\
Nascimento/Maturidade & 2 & $2,27 \%$ \\
Renascimento/Declínio & 2 & $2,27 \%$ \\
Nascimento/Crescimento/Maturidade & 1 & $1,14 \%$ \\
Nascimento/Renascimento/Declínio & 1 & $1,14 \%$ \\
Nascimento/Declínio & 1 & $1,14 \%$ \\
\hline Total & 88 & $\mathbf{1 0 0 , 0 0 \%}$ \\
\hline
\end{tabular}

Nota. Fonte: elaborada pelos autores.

Pela ordem decrescente do número de empresas situadas em cada estágio percebeu-se que a maior parte estava no estágio de "Crescimento", pois 19 respondentes $(21,59 \%$ do total) deram respostas que permitiram esse tipo de classificação. No que se refere ao estágio do "Renascimento", este foi o segundo mais presente na amostra de 88 indústrias de pequeno porte abrangidas porque 16 empresas se enquadravam nesta fase $(18,18 \%$ do total de respondentes). O estágio da "Maturidade" pode ser atribuído a 14 das empresas participantes da pesquisa (15,91\% do total), enquanto que a etapa do "Nascimento" qualifica 12 outras pequenas fábricas (que representam $13,64 \%$ dos respondentes). Além disso, outras quatro empresas puderam ser enquadradas como pertencentes ao estágio de "Declínio", o que equivale a $4,55 \%$ do total abrangido.

Como visto, em 65 empresas $(73,86 \%)$ foi possível determinar o estágio do ciclo de vida dessas organizações. Contudo, em 23 casos $(26,14 \%)$ ocorreu "empate" em mais de um estágio, como apurado no âmbito da empresa "6", onde a soma atingiu 29 
Identificação do estágio do ciclo de vida organizacional de indústrias de pequeno porte do sul de

Santa Catarina

Rodney Wernke, Ivone Junges, Arielle de Jesus Medeiros

pontos nos estágios de "Nascimento" e de "Crescimento". Então, para resolver tal problema foi aplicado o cálculo da entropia da informação, conforme deslindado na próxima seção.

\subsubsection{Aplicação da entropia para apurar o estágio do ciclo de vida das empresas}

Para resolver o impasse relacionado aos "empates" verificados em 23 das 88 indústrias abrangidas foi aplicada a técnica conhecida como entropia. Esse procedimento foi adotado porque em pesquisas que utilizam questionários com respostas em escala "Likert", a entropia necessita de um ponto de referência, ou seja, um valor "âncora" em relação ao qual é calculada a entropia da informação, conforme Rocha (2010). Nesse sentido, caso a escala seja "1" a "5" e o valor 5 seja equivalente a "Concordo", o valor apurado da entropia indicará a quantidade de informação em cada uma das questões testadas. Caso todos os respondentes de uma questão tenham respondido "5 - Concordo", não haverá entropia porque todas as respostas foram idênticas (Rufatto, 2018).

Porém, havendo divergências nas respostas, essas podem afastar a decisão do ponto âncora. Nesse caso, Rocha (2010) argumenta que se pode introduzir mudanças nas di's que causam, correspondentemente, mudanças nas intensidades de contraste relativas. Essas mudanças irão refletir um novo conjunto de $\lambda^{\perp " \sim "} \sim^{i}$ 's, ou seja, a remoção ou adição de uma alternativa pode incrementar a intensidade de contraste e isso produz informação decisória adicional. O oposto também pode ocorrer, ou seja, a riqueza informacional pode ser diminuída nesses casos e os efeitos similares também podem ser removidos ou incluídos. Assim, no âmbito deste estudo a entropia foi utilizada especialmente porque em alguns casos as indústrias abrangidas foram classificadas em mais de uma fase, ou seja, tiveram a mesma pontuação em fases distintas.

Com a aplicação de tal ferramenta o cenário final quanto ao posicionamento das empresas abrangidas nos estágios do ciclo de vida organizacional está exposto na Tabela 5. 
Identificação do estágio do ciclo de vida organizacional de indústrias de pequeno porte do sul de Santa Catarina Rodney Wernke, Ivone Junges, Arielle de Jesus Medeiros

Tabela 5

Classificação por estágios (após a Entropia)

\begin{tabular}{lcc}
\hline Estágios & Quantidade de empresas & Percentual do total \\
\hline Nascimento & 14 & $15,91 \%$ \\
Crescimento & 24 & $27,27 \%$ \\
Maturidade & 21 & $23,86 \%$ \\
Renascimento & 20 & $22,73 \%$ \\
Declínio & 9 & $10,23 \%$ \\
\hline Total & $\mathbf{8 8}$ & $\mathbf{1 0 0 , 0 0 \%}$ \\
\hline
\end{tabular}

Nota. Fonte: elaborada pelos autores.

Portanto, continuou prevalecendo o estágio do "crescimento", que agora participa com 27,27\% das empresas pesquisadas, seguido de perto pelos estágios da "maturidade" $(23,86 \%)$ e do renascimento $(22,73 \%)$. Os estágios de "nascimento" e "declínio" continuaram sendo as fases com menor ocorrência no grupo de fábricas em tela $(15,91 \%$ e $10,23 \%$ respectivamente).

\subsubsection{Mann-Whitney Test}

Adicionalmente foi cogitado se o estágio do ciclo de vida organizacional que prevalece na amostra pesquisada seria o mesmo independentemente dos dois grupos amostrais considerados (o primeiro de empresas com menos de 20 funcionários e 0 segundo com quadro total entre 20 e 99 empregados). Para essa finalidade foi escolhido o Mann-Whitney Test, que é adequado para comparar duas amostras independentes quando verificada a distribuição anormal dos dados (Bruni, 2012).

Soares (2016) argumenta que a estatística deste teste é calculada combinando as observações das duas amostras em uma única variável de tamanho "N1+N2", sendo identificadas as respectivas amostras. Feito isso, essa variável é ordenada (em ordem crescente) e é atribuído o posto 1 à primeira observação, 2 à segunda, e assim por diante. No caso de empates, é atribuído o posto médio que essas observações teriam se não fossem empates. Em seguida, calcula-se a soma dos 
Identificação do estágio do ciclo de vida organizacional de indústrias de pequeno porte do sul de

Santa Catarina

Rodney Wernke, Ivone Junges, Arielle de Jesus Medeiros

postos das observações de cada amostra (W1 e W2), onde são calculadas as quantidades por intermédio das equações a seguir:

$$
\begin{aligned}
& U_{1}=N_{1} N_{2}+\frac{N_{2}\left(N_{2}+1\right)}{2}-W_{2} \\
& U_{2}=N_{1} N_{2}+\frac{N_{1}\left(N_{1}+1\right)}{2}-W_{1}
\end{aligned}
$$

Então, analisou-se a hipótese nula $(\mathrm{H} 0)$ de que o estágio do ciclo de vida organizacional que prevalece é igual entre os dois grupos de empresas pesquisadas e o resultado oriundo do SPSS pode ser resumido conforme consta da Tabela 6.

Tabela 6

Resultados do Mann-Whitney Test

\begin{tabular}{lrr}
\hline \multicolumn{1}{c}{ Itens } & N & Mean Rank \\
\hline Grupo 1 - Empresas com até 19 empregados & 30 & 47,93 \\
Grupo 2 - Empresas com total de empregados entre 20 e 99 & 58 & 42,72 \\
Total & 88 & - \\
\hline Mann-Whitney U & & 767 \\
Wilcoxon W & & 2478 \\
Z & & $-0,926$ \\
Sig. Assint. (2 caudas) & 0,355 \\
\hline
\end{tabular}

Nota. Fonte: elaborada pelos autores.

A Tabela 6 apresenta um posto médio (mean rank) para os grupos citados, respectivamente iguais 47,93 e 42,72. O teste de hipóteses apresentou uma estatística Z igual a -0,926, com nível de significância igual a 0,355. Com isso, rejeita-se a hipótese nula $(\mathrm{H} 0)$ e aceita a hipótese alternativa $(\mathrm{H} 1)$, o que equivale a supor que as médias dos dois grupos não sejam iguais porque o "Grupo 1 - Até 19 empregados" apresentou uma média maior, significativamente diferente da média do segundo agrupamento.

Desse modo, encontrou-se evidências estatísticas nessa amostra de 88 indústrias de pequeno porte de que há diferenças no estágio do ciclo de vida organizacional que prevalece se comparados os dois grupos de empresas citados. 
Identificação do estágio do ciclo de vida organizacional de indústrias de pequeno porte do sul de

Santa Catarina

Rodney Wernke, Ivone Junges, Arielle de Jesus Medeiros

\subsection{Cotejamento com pesquisas anteriores}

Da lista mencionada de estudos precedentes assemelhados, dois foram os que mais se aproximaram do foco deste artigo e permitem um confronto, mesmo que parcial, dos resultados.

Embora tenha visado um conjunto de empresas industriais com faturamento anual superior a $\mathrm{R} \$ 500$ mil, na pesquisa de Santos, Corrêa, Beuren e Gomes (2019) os resultados se mostraram diferentes deste estudo quanto à predominância do estágio do ciclo de vida. Ou seja, constataram que a maioria das empresas abrangidas se encontrava no estágio de "nascimento". Contudo, no contexto das pequenas empresas industriais da Amurel foi verificado que prevaleceu o estágio do "crescimento" (27,27\% das fábricas pesquisadas), seguido pelos estágios da "maturidade" $(23,86 \%)$ e do "renascimento" (22,73\%). Ou seja, os estágios de "nascimento" e "declínio" foram os de menor ocorrência no grupo de fábricas em tela (15,91\% e 10,23\% respectivamente). Por outro lado, houve uma similaridade nos resultados desses dois estudos no que concerne ao não seguimento da ordem determinística associada à evolução das empresas dentro da teoria sobre o ciclo de vida organizacional.

No caso da pesquisa de Almeida e Wernke (2018), o foco também foi em pequenas empresas (como neste artigo), mas utilizou um modelo diferente para identificar o ciclo de vida organizacional. Nesse rumo, o citado estudo evidenciou que, num grupo de 45 firmas, a maior parte (19 empresas) estava no estágio de "Consolidação" (que equivale ao terceiro estágio no modelo que utilizaram). Além disso, mostraram que 16 daquelas empresas estavam no estágio "2" (Direção) e apenas 10 empresas foram classificadas no estágio "1" (Estabelecimento). Portanto, tal realidade de certa forma se assemelha aos resultados evidenciados nesta pesquisa, pois há prevalência dos estágios posteriores ao período inicial (de "nascimento" ou "estabelecimento"). 
Identificação do estágio do ciclo de vida organizacional de indústrias de pequeno porte do sul de

Santa Catarina

Rodney Wernke, Ivone Junges, Arielle de Jesus Medeiros

\section{CONCLUSÕES}

O objetivo do artigo foi identificar o estágio do ciclo de vida organizacional que prevalece nas pequenas empresas fabris localizadas nos municípios da microrregião da AMUREL e, adicionalmente, encontrar resposta para indagação acerca de que o estágio do ciclo de vida dessas empresas poderia estar associado ao número de funcionários que essas mantêm.

Nesse sentido, os autores consideram que tal finalidade foi atingida porque a tabulação das respostas permitiu conhecer os estágios do ciclo de vida que prevalecem no contexto das empresas abrangidas, além de obter indicativo estatístico de que o estágio do ciclo de vida da empresa tende a ser afetado pelo número de funcionários mantidos pelas empresas da amostra utilizada no estudo.

Quanto aos resultados mais relevantes, cabe salientar os seguintes aspectos:

1) Os estágios do ciclo de vida identificados foram, em ordem decrescente, "crescimento" (27,27\%), "maturidade" $(23,86 \%)$, renascimento $(22,73 \%)$, "nascimento" (15,91\%) e "declínio" (10,23\%);

2) A hipótese de pesquisa que cogitava não haver interferência do número de funcionários no estágio do ciclo de vida da empresa foi rejeitada, pois os dois grupos amostrais mostraram médias distintas do ponto de vista estatístico pelo Mann-Whitney Test.

No que tange às contribuições desta pesquisa, do ponto de vista gerencial essas se assentam principalmente no fato de que permitiu conhecer a realidade das pequenas empresas fabris de uma microrregião do sul de Santa Catarina quanto aos estágios dessas em termos do ciclo de vida organizacional. No âmbito teórico, considera-se que contribuiu no sentido de constatar a aderência do modelo de Miller e Friesen (1984) nesse contexto empresarial, além de apontar evidências estatísticas sobre a influência do porte empresarial (medido pelo número de funcionários) no estágio do ciclo de vida de pequenas empresas. 
Identificação do estágio do ciclo de vida organizacional de indústrias de pequeno porte do sul de

Em relação às limitações da pesquisa convém ressaltar alguns pontos. $\mathrm{O}$ primeiro diz respeito ao tamanho da amostra utilizada, pois as 88 pequenas indústrias estudadas foram aquelas que concordaram em participar. Portanto, com fulcro nesse critério os resultados oriundos não podem ser extrapolados para outros contextos empresariais ou regionais. O segundo ponto refere-se ao fato de que foi utilizado um questionário padronizado, cujas questões podem levar a interpretações equivocadas dos respondentes. Ou seja, não foram checadas/trianguladas as respostas obtidas nos controles internos das firmas abrangidas, assumindo-se que as respostas coligidas representam a realidade dessas empresas.

Quanto às recomendações para pesquisas futuras, seria interessante expandir o número de empresas envolvidas, bem como aplicar estudo assemelhado em outras regiões do país (ou outros países) a fim de comparar os resultados.

\section{REFERÊNCIAS}

Adizes, I. (1990). Os ciclos de vida das organizações: como e por que as empresas crescem e morrem e o que fazer a respeito. São Paulo: Pioneira.

Almeida, F. M., Valadares, J. L., \& Sediyama, G. A. S. (2017). A contribuição do empreendedorismo para o crescimento econômico dos estados brasileiros. Revista de Empreendedorismo e Gestão de Pequenas Empresas, 6(3), 466-494.

Almeida, I. X., \& Wernke, R. (2018). Estilos gerenciais dos dirigentes de pequenas empresas: estudo baseado no ciclo de vida organizacional. Revista de Empreendedorismo e Gestão de Pequenas Empresas, 7(3), 110-140.

Andrade, M. M. de. (2002). Como preparar trabalhos para cursos de pós-graduação: noções práticas. (5a ed.). São Paulo: Atlas.

Auzair, S. M., Langfield-Smith, K. (2005). The effect of service process type, business strategy and life cycle stage on bureaucratic MCS in service organizations. Management Accounting Research, 16(4), 399-421.

Beuren, I. M., \& Oliveira, A. F. (2015). Mudanças nos imperativos da configuração organizacional com a crise Subprime e suas relações com a controladoria. Revista Organizações em Contexto, 11(22), 1-45. 
Identificação do estágio do ciclo de vida organizacional de indústrias de pequeno porte do sul de

Santa Catarina

Rodney Wernke, Ivone Junges, Arielle de Jesus Medeiros

Beuren, I. M., Rengel, S., \& Rodrigues Junior, M. M. (2015). Relação dos atributos da contabilidade gerencial com os estágios do ciclo de vida organizacional. Innovar, 25(57), 63-78.

Bruni, A. L. (2012). SPSS: guia prático para pesquisadores. São Paulo: Atlas.

Callado, A. A. C. (2016). Relações entre o número de indicadores de desempenho utilizados e fatores contingenciais: evidências do contexto de uma cadeia agroalimentar de suprimentos. Revista Contabilidade Vista \& Revista, 27(2), 48-63.

Campos, H. M., Parellada, F. S., Atondo, G. H., \& Quintero, M. R. (2015). Strategic decision making, entrepreneurial orientation and performance: an organizational life cycle approach. Revista de Administração FACES, 14(2), 8-24.

Carpes, A. M. S. (2015). Mecanismos de governança corporativa nos diferentes estágios de ciclo de vida das cooperativas agropecuárias do sul do Brasil. 2015. (Tese de Doutorado em Ciências Contábeis e Administração). Programa de PósGraduação em Ciências Contábeis da Universidade Regional de Blumenau. Blumenau.

Carvalho, K. L., Saraiva Junior, A. F., Frezatti, F., \& Costa, R. P. (2010). A contribuição das teorias do ciclo de vida organizacional para a pesquisa em contabilidade gerencial. Revista de Administração Mackenzie, 11(4), 1-10.

Dickinson, V. (2011). Cash flow patterns as a proxy for firm life cycle. The Accounting Review, 86(6), 1969-1994.

Dufour, Y., Steane, P., Corriveau, A. M. (2018). From the organizational life-cycle to "ecocycle": a configurational approach to strategic thinking. Asia-Pacific Journal of Business Administration, 10(2/3), 171-183.

Faveri, D. B., Cunha, P. R., Santos, V., \& Leandro, D. A. (2014). Relação do ciclo de vida organizacional com o planejamento: um estudo com empresas prestadoras de serviços contábeis do estado de Santa Catarina. Revista de Educação e Pesquisa em Contabilidade, 8(4), 382-402.

Field, A. (2009). Descobrindo a estatística usando o SPSS. Porto Alegre: Artmed.

Frezatti, F., Bido, D. de S., Mucci, D. M., \& Beck, F. (2017). Estágios do ciclo de vida e perfil de empresas familiares brasileiras. Revista de Administração de Empresas $R A E, 57(6), 601-619$. 
Identificação do estágio do ciclo de vida organizacional de indústrias de pequeno porte do sul de

Santa Catarina

Rodney Wernke, Ivone Junges, Arielle de Jesus Medeiros

Gil, A. C. (2002). Como elaborar projetos de pesquisa. (4a ed.). São Paulo: Atlas.

Greiner, L. E. (1998). Evolution and revolution as organizations grow-Larry E. Greiner responds. Harvard Business Review, 76(4), 178-179.

Klann, R. C., Klann, P. A., Postai, K. R., \& Ribeiro, M. J. (2012). Relação entre o ciclo de vida organizacional e o planejamento em empresas metalúrgicas do município de Brusque-SC. Revista de Contabilidade e Organizações, 6(16), 119-142.

Klein, L., \& Almeida, L. B. (2017). A influência dos fatores contingenciais na adoção de práticas de contabilidade gerencial nas indústrias paranaenses. Revista Universo Contábil, 13(3), 90-119.

Lester, D. L., Parnell, J. A., \& Carraher, S. (2003). Organizational life cycle: a five-stage empirical scale. The International Journal of Organizational Analysis, 11(4), 339354.

Lima, M. S., \& Vasconcelos, A. C. de. (2016). Ciclo de vida organizacional e ativos intangíveis de empresas de base tecnológica incubadas. Revista de Administração de Roraima - RARR, 6(1), 128-155.

Malik, K., \& Jasinska-Biliczak, A. (2018). Innovations and other processes as identifiers of contemporary trends in the sustainable development of SMEs: the case of emerging regional economies. Sustainability, 10(5),1361.

Manzardo, A., Loss, A., Jingzheng, R. Filippo, Z., \& Scipioni, A. (2018). Definition and application of activity portfolio and control/influence approaches in organizational life cycle assessment. Journal of Cleaner Production, 184, 264.

Marques, L., Cunha, P. R., Faveri, D. B., \& Walter, F. M. (2014). Relação entre o ciclo de vida organizacional e o processo orçamentário em empresas metal-mecânicas do alto e médio Vale do Itajaí. Enfoque: Reflexão Contábil, 33(2), 1-18.

Meirelles, B. O., Debastiani, S. M., \& Rojo, C. A. (2015). Proposta de intervenção empresarial com base no ciclo de vida organizacional proposto por Greiner: o caso da Scherer Indústria de Implementos Agrícolas. Revista Capital Científico-Eletrônica (RCCe), 13(3), 111-123.

Miller, D., \& Friesen, P. H. (1984). A longitudinal study of corporate life cycle. Management Science, 30(10), 1161-1183. 
Identificação do estágio do ciclo de vida organizacional de indústrias de pequeno porte do sul de

Santa Catarina

Rodney Wernke, Ivone Junges, Arielle de Jesus Medeiros

Moores, K., \& Yuen, S. (2001). Management accounting systems and organizational configuration: a life-cycle perspective. Accounting, Organizations and Society, 26(4), 351-389.

Moreira, L.V. M. (2016). Sistema de controle gerencial como fator de influência no ciclo de vida organizacional de empresas familiares. 2016. $111 \mathrm{f}$. (Dissertação de Mestrado em Ciências Contábeis). Programa de Pós-Graduação em Controladoria e Contabilidade, Universidade de São Paulo - USP. São Paulo.

Moterle, S., Wernke, R., \& Junges, I. (2019). Conhecimento sobre gestão financeira dos dirigentes de pequenas empresas do Sul de Santa Catarina. RACE, Revista de Administração, Contabilidade e Economia, 18(1), 1-26. Recuperado de: http://editora.unoesc.edu.br/index.php/race.

Nigri, G., \& Baldo, M. (2018). Sustainability reporting and performance measurement systems: how do small-and medium-sized benefit corporations manage integration? Sustainability, 10(12), 1-17.

Oliveira, J., Escrivão Filho, E., Nagano, M. S., \& Ferraudo, A. S. (2015). Estilos gerenciais dos dirigentes de pequenas empresas: estudo baseado no ciclo de vida organizacional e nos conceitos de funções e papéis do administrador. Revista Brasileira de Gestão de Negócios, 17(57), 1279-1299.

Otley, D. T. (1980). The contingency theory of management accounting: Achievement and prognosis. Accounting, Organizations and Society, 5(4), 413-428.

Pinheiro, R. W., Silva, W. A. C., \& Araújo, E. A. T. (2013). Análise conjunta do ciclo de vida e da longevidade empresarial: um enfoque em indústria, comércio e agronegócio. Revista de Negócios, 18(3), 37-57.

Primc, K., \& Cater, T. (2016). The influence of organizational life cycle on environmental proactivity and competitive advantage: as dynamic capabilities view. Organization and Environment, 29(2), 212-230.

Quinn, R. E., \& Cameron, K. (1983). Organizational life cycles and shifting criteria of effectiveness: some preliminary evidence. Management Science, 29(1), 33-51.

Rauen, F. (2015). Roteiros de iniciação científica: os primeiros passos da pesquisa científica desde a concepção até a produção e a apresentação. Palhoça: Editora Unisul.

Richardson, R. J. (1999). Pesquisa social: métodos e técnicas. São Paulo: Atlas. 
Identificação do estágio do ciclo de vida organizacional de indústrias de pequeno porte do sul de

Santa Catarina

Rodney Wernke, Ivone Junges, Arielle de Jesus Medeiros

Rocha, I. (2010). Grau de entropia da informação em indicadores econômico-financeiros das empresas que participam dos níveis de governança corporativa da BM\&FBovespa. 2010. 155 f. (Dissertação de Mestrado em Ciências Contábeis). Universidade Regional de Blumenau, Blumenau.

Rufatto, I. (2018). Níveis de utilização e de importância das práticas de controladoria adotadas por cooperativas agrícolas paranaenses. 2018. 167 f. (Dissertação de Mestrado em Contabilidade e Administração). Programa de Pós-graduação em Contabilidade e Administração, Universidade Comunitária da Região de Chapecó. Chapecó.

Santos, F. O. (2014). Avaliação do sistema de controle gerencial sob a influência de fatores contingenciais: estudo de caso em um grupo econômico. 2014. $84 \mathrm{f}$. (Dissertação de Mestrado em Contabilidade e Controladoria). Programa de Pósgraduação em Contabilidade e Controladoria, Universidade Federal do Amazonas. Manaus.

Santos, J. E. A. (2017). Inovação e ciclo de vida organizacional: o caso do setor de produção de cachaça da Paraíba. 2017. 171 f. (Dissertação de Mestrado em Administração). Programa de Pós-graduação em Administração, Universidade Federal da Paraíba. João Pessoa.

Santos, V., Dorow, D. R., \& Beuren, I. M. (2016). Práticas gerenciais de micro e pequenas empresas. Revista Ambiente Contábil, 8(1), 153-186.

Santos, V. dos, Corrêa, N. L., Beuren, I. M., Gomes, T. (2019). Relação entre ciclo de vida organizacional e uso de instrumentos de contabilidade gerencial. Enfoque: Reflexão Contábil, 39(2), 67-85.

Serviço Brasileiro de Apoio às Micro e Pequenas Empresas - SEBRAE. (2019). Critérios de classificação do porte da empresa. Recuperado de: <http://www.sebraesc.com.br/leis/default.asp>. Acesso em: 12/mar./2019.

Silva, J. M. (2016). A influência do ciclo de vida organizacional sobre o nível de planejamento tributário. 2016. 213 f. (Tese de Doutorado em Controladoria e Contabilidade). Programa de Pós-Graduação em Controladoria e Contabilidade, Faculdade de Economia, Administração e Contabilidade da Universidade de São Paulo. São Paulo.

Silva, L. C. (2008). Controles de gestão utilizados nas fases do ciclo de vida das indústrias familiares do polo moveleiro de São Bento do Sul/SC. 2008. $208 \mathrm{f}$. (Dissertação de Mestrado em Ciências Contábeis). Programa de Pós-Graduação da Universidade Regional de Blumenau. Blumenau. 
Identificação do estágio do ciclo de vida organizacional de indústrias de pequeno porte do sul de

Santa Catarina

Rodney Wernke, Ivone Junges, Arielle de Jesus Medeiros

Soares, C. S. (2016). Mensuração da performance social corporativa com dados extraídos do relatório de sustentabilidade da GRI. 2016. 118 f. (Dissertação de Mestrado em Administração). Programa de Pós-Graduação em Administração e Contabilidade, Universidade de São Paulo - USP. São Paulo.

Souza, R. P., Guerreiro, R., \& Oliveira, M. P. V. (2015) Relationship between the maturity of supply chain process management and the organizational life cycle. Business Process Management Journal, 21(3), 466-481.

Souza, B. C. de, Necyk, G. A., \& Frezatti, F. (2008). Ciclo de vida das organizações e a contabilidade gerencial. Enfoque: Reflexão Contábil, 27(1), 9-22.

Su, S., Baird, K., Schoch, H. (2015). The moderating effect of organizational life cycle stages on the association between the interactive and diagnostic approaches. Management Accounting Research, 26(1), 40-53.

Tam, S., \& Gray, D. E. (2016). The practice of employee learning in SME workplaces. Journal of Small Business and Enterprise Development, 23(3), 671-690.

TenBrink, C., \& Gelb, B. (2017). When firms mature: keeping the ho-hum at bay and embracing change. Journal of Business Strategy, 38(5), 12-17.

Triola, M. F. (2005). Introdução à estatística. 9ª ed. Rio de Janeiro: LTC.

Yh, Y., Kh, L., \& Hj, K. (2016). Closure of a local public hospital in Korea: focusing on the organizational life cycle. Journal of Healthcare Leadership, 8, 95-105.

Data de Submissão: 26/11/2019

Data de Aceite: 01/10/2020 